$\begin{array}{ll}\text { Research Square } & \begin{array}{l}\text { Preprints are preliminary reports that have not undergone peer review. } \\ \text { They should not be considered conclusive, used to inform clinical practice, } \\ \text { or referenced by the media as validated information. }\end{array}\end{array}$

\title{
Prevalence, Risk factors and Antibiogram analysis of Nosocomial Infection in Tertiary Care Hospital of Rawalpindi, Pakistan
}

Jadoon Khan ( $\nabla$ jadoonkhanzoologist@gmail.com )

Quaid-i-Azam University Faculty of Biological Sciences https://orcid.org/0000-0002-7302-6987

Israr Ahmad

Rawalpindi Medical University

Nosheen Basharat

COMSATS University Islamabad

Alam Khan

Quaid-i-Azam University Faculty of Biological Sciences

Asma Sadiq

COMSATS University Islamabad

Shahid Ali

Quaid-i-Azam University Faculty of Biological Sciences

Muhammad Sohail

Lanzhou University School Of Life Sciences

Allah Nawaz Khan

Iqra University - Islamabad Campus

ljaz Ahmad

Kindai University Faculty of Medicine Graduate School of Medical Sciences: Kinki Daigaku Igakubu Daigakuin Igaku Kenkyuka saddam saddam

Abdul Wali Khan University Mardan

Aamir Aziz

Sarhad University of Science and Information Technology

Hayat Khan

University of Swabi

ljaz Ali

COMSATS University Islamabad

Research

Keywords: NIs, HCAI, WBCs, UTI, MRSA, hematology, biochemistry, electrolyte, microbial analysis

Posted Date: January 15th, 2021

DOI: https://doi.org/10.21203/rs.3.rs-145858/v1

License: (1) This work is licensed under a Creative Commons Attribution 4.0 International License. Read Full License 


\section{Abstract}

Background

Nosocomial infections are a global health problem, affecting 1.4 million people in treatment centers, responsible for 80,000 estimated annual deaths. The current study aimed to assess the factor influencing nosocomial infections and to choose the best antibiotic for its treatment through culture analysis.

Methodology

The current study was conducted in a tertiary care hospital Rawalpindi. A total of 120 patients with at least one nosocomial episode were included. Blood, urine, and wound swab sample were collected for hematology, biochemistry, electrolyte, and microbial analysis. Multivariate regression analysis through SPSS (ver. 16.0) were done, p-value of $\leq 0.05$ was considered statistically significant.

Result

The prevalence of culture-confirmed nosocomial infection was $25 \%$, among which age groups $(\mathrm{P}=0.00,95 \% \mathrm{Cl},-.382-.271)$ were significantly correlated. Hematological analysis shows that $73.3 \%$ have lymphopenia $(P=0.00,95 \% \mathrm{Cl} .567-1.175), 73.3 \%$ have Neutrocytosis $(P=0.00,95 \% \mathrm{Cl} .553-1.122)$ and anemia (26.7\%) ( $P=0.002,95 \% \mathrm{Cl} .097-.404)$ were statistically significant. Raised level of ALT (60\%), Bilirubin (26.7\%) and ALP (13.3\%) among liver functional tests $(P=0.68,95 \% \mathrm{Cl} .686-.280)$ found insignificant however abnormal level of urea (33.3\%) and creatinine $(46.7 \%)(P=0.00,95 \% \mathrm{Cl}-1.227-.392)$ were significantly correlated with nosocomial infections. Electrolytes profile shows that Hypernatremia $(26.7 \%)(\mathrm{P}=0.000,95 \% \mathrm{Cl}$-491-.227) were strongly correlated. Culture analysis isolated six bacterial agents, comprising 83.3\%:16.6\% ratio of gram-negative and gram-positive isolates. Klebsiella pneumonia was frequently isolated gram-negative, while Methicillin-Resistant Staphylococcus aureus was the only gram-positive isolate collected. Urinary tract infection (UTI) (36.6\%) was frequently found, followed by bloodstream infection (26.6\%) (BSI). The majority of the gram-negative isolates were sensitive to Imipenem while resistant to Amoxicillin + Clavulanic acid, Trimethoprim/sulfamethoxazole, cefoxitin, Levofloxacin, Norfloxacin, and linezolid antibiotics. Methicillinresistant staphylococcus aureus was found sensitive against Trimethoprim/sulfamethoxazole while resistant towards linezolid, Imipenem, and Cefotaxime.

Conclusion

The current study revealed that nosocomial infection is still prevalent in our hospital environment and the leading cause of drug resistance and dysfunctions of various factors like WBCs, LFTs, RFTs, electrolytes, coagulation factors and anemia, which can lead to morbidity and mortality.

\section{Introduction}

Nosocomial Infections (NIs) or Hospital-acquired infection (HAls), or Healthcare-associated infections (HCAls) are those infections that occur within 48 hours of hospitalization or during 30 days after taking treatment from a hospital $(1,2)$. A worldwide survey conducted by WHO shows that 1.4 million peoples remain infected from Nosocomial infection at any time, responsible for 80,000 deaths per year $(3,4)$. The developing countries are 2 to 20 times more susceptible to NIs, accounts for $10 \%$ infections than developed countries having $7 \%$ of us $(5,6)$. Various negative impacts of NIs includes an excess amount of financial loss for the patients and their family due to treatment difficulties and prolonged hospital stay, increasing antimicrobial resistance, long-term disabilities, and increase death ratio (7). Diagnosis of us is still a global problem because it relies on multiple criteria, not on a single diagnostic test, and a lack of attention of national systems of continuous surveillance. Nosocomial Infections are founds in every setting, from ambulatory to long term hospital care, an alternative problem that no institution or country can claim to have solved yet (7). NIs is a global health-care problem; however, the global burden is unknown due to a lack of reliable diagnostic data (7). Nls are 2-5 times more prominent inside the intensive care unit (ICU) than in the general population (8) responsible for inducing morbidity and mortality, which is a matter of grave concern today (9).

Various Bacterial, viral and fungal pathogens are involved in Nosocomial infections(5); however, most of them are caused by bacteria, including normal flora (cause infection only in immune-compromised/immunosuppressed individuals (10). In the majority (80 to $87 \%$ ) of Nls, 12 to 17 various pathogens, including Bacteroides species, Candida species (e.g., Albicans, glabrate), Yeast NOS, Proteus species, Enterobacter species, A. baumannii, P. aeruginosa, Klebsiella oxytoca, and K. pneumonia, coagulase-negative Staphylococci, E. coli, Enterococcus species (e.g., faecium and faecalis), S. aureus, and other pathogens are involved (11-13). These pathogens consist of 16-20\% Multidrug-resistant isolates like carbapenem-resistant A. baumannii, Enterobacter species, E. coli, K. oxytoca, P. aeruginosa, extended-spectrum cephalosporin-resistant Enterobacter species, E. coli, K. oxytoca, K. pneumonia, vancomycin-resistant E. faecium, and Methicilin resistant Staphylococcus aureus (MRSA) $(11,12)$.

Various factors such as immune status of the patients, the bacterial population at the infection site, mechanism of action of antibiotics, the quantity of antibacterial reach to the bacterial community (14-17), induce usage of invasive materials, substandard infection control strategies, the congested environment of the hospitals and over the counter antibiotic use leads to the development of high antimicrobial resistance, especially in developing countries (18). According to a large surveillance study, around $70 \%$ of the ICU admitted patients are using antibiotics either as prophylaxis or for treatment purposes(19). In the recent era, most of the antibiotics become non-effective against bacterial infections leads to the failure of routine treatment (20), induces patient morbidity, mortality, and healthcare-related expenses $(21,22)$. Keeping the above literature in view, the present study was designed to analyze the various hematological, physiological changes, and antimicrobial profiles among ICU-admitted hospital-acquired infection patients.

\section{Methodology}

\section{Ethics Statement and Informed Consent}


The ethical review committee of Rawalpindi Medical University approved the current study (S/No. 12-13/RMU-2019). The patients were informed about the research study before sample collection. A written consent form consists of name, age, gender, date of admission, clinical settings, the reason for hospitalization, type of pathology, type of infection, and the number of days spent in the hospital before admission into ICU and start of the first nosocomial infection were filled appropriately.

\section{Study design}

The current study was carried out between 1st February 2019, and 31st January 2020 at District headquarter Hospital affiliated with Rawalpindi Medical University, Rawalpindi, Pakistan. During this study, we included all the patients admitted for more than 48 hours to the Intensive Care Unit (ICU), with no signs of bacterial colonization at the time of admission. Those patients who don't fulfill the above criteria were excluded from the study. The suspected patients of nosocomial infection were clinically examined by physicians to exclude community-acquired infection.

\section{Sample Collection and Processing}

A total of 120 patients were studied who were admitted to the ICU of the hospital, among which 30/120 (25\%) patients developed at least one nosocomial episode. Various samples, including $5 \mathrm{cc}$ of blood, wound swab, and $10-20 \mathrm{ml}$ of urine in a sterile, dry, wide-necked, leak-proof container were collected using standard procedures described by Horan et al.(23). The specimens were labeled with the patient's identification, packed and transported within 30 minutes of the collection in a cold box to the pathology and microbiology Laboratory for further analysis.

\section{Hematological Analysis}

Analysis of the samples' various hematological assessments, including complete blood count (CBC) and hemoglobin, was carried out on unique automated analyzer SYSMEX XP 100 (19 Jln Tukang, Singapore 619257). Different biochemical tests such as Serum Creatinine, Serum Bilirubin, Alanine transaminase (ALT), Aspartate transaminase (AST), Alkaline phosphatase (ALP), Prothrombin time (PT), and Urea were evaluated through AU480 Chemistry Analyzer (Bakman colter 400). Electrolytes (Sodium, Potassium, and Chlorides) analysis was performed through the EasyLyte analyzer (Medica Corporation, 5 Oak Park Drive, Bedford, MA 01730, USA).

\section{Microbial analysis and Phenotypic Characterization of the Isolates}

Samples were inoculated on Blood agar (Oxoid, UK), MacConkey agar (Oxoid, UK), and of Cystine Lactose-Electrolyte-Deficient Agar (CLED) agar followed by incubation of the plate aerobically at $35-37^{\circ} \mathrm{C}$ for 24 hours. The entire bacterial isolates were phenotypically characterized through their culture uniqueness and biochemical tests as earlier by Cheesbrough, (2006). Briefly, various differential and selective culture media (Oxoid, Ltd., UK), like Blood agar, Chocolate (heated blood) agar, and MacConkey agar, were used for inoculation and investigation of bacterial isolates. Various bacterial isolates were characterized through their cellular morphology, the morphology of their colony, and colonial pigmentation. Bacterial Species were characterized through various biochemical tests like catalase, oxidase, coagulase, urease, and motility tests. After overnight incubation at $37^{\circ} \mathrm{C}$, the reading of the culture were performed by two senior medical microbiologists.

\section{Antibiogram Analysis}

In vitro antibiogram analysis was performed according to the Kirby Bauer disk diffusion method based upon the criteria of Clinical and Laboratory Standards Institute criteria (CLSI, 2015). In brief, standard inoculum adjusted to $0.5 \mathrm{McFarland}$ standard turbidity was uniformly distributed over Mueller Hinton agar (Oxoid, Ltd., UK). Antimicrobial disks, including (Oxoid, Ltd., UK), Cefixime $(5 \mu \mathrm{g})$, Cefoxitin $(10 \mu \mathrm{g})$, Erythromycin $(5 \mu \mathrm{g})$, Ciprofloxacin $(5 \mu \mathrm{g}), \mathrm{Linezolid}(30 \mu \mathrm{g})$, Meropenem $(10 \mu \mathrm{g})$, Imipenem $(10 \mu \mathrm{g})$, Cefoperazone/Sulbactam $(30 \mu \mathrm{g})$, Ceftazidime $(30 \mu \mathrm{g})$, Amikacin $(30 \mu \mathrm{g})$, Vancomycin $(30 \mu \mathrm{g})$, Chloramphenicol $(30$ $\mu \mathrm{g})$, Gentamicin $(10 \mu \mathrm{g})$, Tobramycin $(10 \mu \mathrm{g})$, and Erythromycin $(15 \mu \mathrm{g})$ were applied with the help of automatic disk dispenser on Mueller Hinton agar plates and incubated overnight at $37^{\circ} \mathrm{C}$. The sensitive, intermediate sensitive, and resistant isolates were investigated by measuring their respective inhibition zone as per standard criteria (24). Any bacterial isolate found resistant to at least one antimicrobial in three or more antibiotics having different structural categories was considered multidrug-resistant (MDR) isolate(25).

\section{Statistical Analysis}

For statistical logistic multivariate regression analysis, SPSS for Windows version 16.0 (SPSS Inc., Chicago, IL, USA) was used. $P$ values $<0.05$ were considered significant.

\section{Results}

\section{Distribution of Initial Diagnosis}

The entire studied patients were admitted due to various complications, like (25\%) RTA, 18.3\% EXP, 10\% FAl, 6.67\% Head Injury, 5\% spinal injury, and a Stab wound. Dengue infection and acute SDH, and Gynae consist of 3.3\% each, while 1.6\% each of ICB, SOL, Poisoning, DKA, EVD/Meningitis, Nephrotic disease, Trauma, Gastric Ulcer, Parietal EDH, Post Nephrectomy, Pneumonia, Gangrene and Pelvic Injury each respectively.

\section{Age and Gender-Wise Distribution of Nosocomial Infections}

Among the 120 patients studied male and female were in 86.7:13.3 ratio non-significant $(\mathrm{P}=0.83,95 \% \mathrm{Cl}-.139-.171, \mathrm{R}=0.538)$ respectively. They were divided into five age groups, and the effect of Nosocomial Infection was significantly correlated ( $\mathrm{P}=0.00,95 \% \mathrm{Cl},-.382-.271, \mathrm{R}=0.538)$, as shown in table 3.1 . 
Table 3.1. Age and Gender-Wise Distribution of Nosocomial Infections

\begin{tabular}{|c|c|c|c|c|c|c|c|}
\hline \multirow{2}{*}{$\begin{array}{l}\text { Variable } \\
\text { Age }\end{array}$} & \multirow{2}{*}{$\begin{array}{l}\text { Groups } \\
5-20 \text { Years }\end{array}$} & \multirow{2}{*}{$\begin{array}{l}\text { Frequency } \\
16 / 120(13.3 \%)\end{array}$} & \multirow{2}{*}{$\begin{array}{l}\text { t-value } \\
-11.613\end{array}$} & \multirow{2}{*}{$\begin{array}{l}\text { P-value } \\
.000\end{array}$} & \multicolumn{2}{|c|}{ 95\% Confidence Interval } & \multirow{2}{*}{$\begin{array}{l}\text { R-Square } \\
0.538\end{array}$} \\
\hline & & & & & -.382 & -.271 & \\
\hline & 21-35 Years & $32 / 120(26.7 \%)$ & & & & & \\
\hline & $36-50$ Years & $44 / 120(36.7 \%)$ & & & & & \\
\hline & $>50$ years & $28 / 120(23.3 \%)$ & & & & & \\
\hline \multirow[t]{2}{*}{ Gender } & Male & $104 / 120(86.7 \%)$ & .208 & .835 & -.139 & .171 & \\
\hline & Female & $16 / 120(13.3 \%)$ & & & & & \\
\hline
\end{tabular}

Hematological Analysis:

Hematological analysis performed for NIs are given below;

\section{Total Leukocytes count}

Among the 30 confirmed patients with nosocomial infection , $73.3 \%$ have lymphopenia ( $\mathrm{P}=0.00,95 \% \mathrm{Cl} .567-1.175, \mathrm{R}=0.226)$ and $73.3 \%$ have Neutrocytosis $(P=0.00,95 \% \mathrm{Cl} .553-1.122, R=0.226)$ significantly correlated with nosocomial infection as shown in the table 3.2.

Table 3.2. Total Leukocyte count in culture-positive Nosocomial Infection

\begin{tabular}{|c|c|c|c|c|c|}
\hline \multirow[t]{2}{*}{ Characteristic } & \multirow[t]{2}{*}{ T-value } & \multirow[t]{2}{*}{ P-value } & \multicolumn{2}{|c|}{ 95\% Confidence Interval } & \multirow{2}{*}{$\begin{array}{l}\text { R-square } \\
0.226\end{array}$} \\
\hline & & & Lower Boundries & Upper Boundries & \\
\hline Leukocytosis & -.716 & .475 & -.249 & .117 & \\
\hline Thrombocytopenia & -.637 & .525 & -.225 & .116 & \\
\hline Lymphopenia & 5.667 & .000 & .567 & 1.175 & \\
\hline Neutrocytosis & 5.834 & .000 & .553 & 1.122 & \\
\hline Erythrocytopenia & -1.311 & .192 & -.254 & .052 & \\
\hline
\end{tabular}

\section{Coagulation Profile and Anemia}

Among nosocomial patients, 33.3\% have thrombocytosis ( $P=0.75,95 \% \mathrm{Cl}-.201-.145, \mathrm{R}=0.012)$ were in-significant however $26.7 \%$ were found anemic $(P=0.002,95 \% \mathrm{Cl} .097-.404, \mathrm{R}=0.092)$ were found statistically significant as shown in the table 3.3 .

Table. 3.3 Coagulation Profile and Anemia among Culture-confirmed Nosocomial Infection

\begin{tabular}{|lccccc|}
\hline Characteristic & T-value & P-value & \multicolumn{2}{l}{$\mathbf{9 5 \% \text { Confidence Interval }}$} & R-square \\
\cline { 3 - 6 } & & & Lower Boundries & Upper Boundries & $\mathbf{0 . 0 1 2}$ \\
Platelets & -.318 & .751 & -.201 & .145 & \\
PT & 1.209 & .229 & -.177 & .733 & \\
APTT & 1.171 & .244 & -.179 & .696 & $\mathbf{0 . 0 9 2}$ \\
Anemia & 3.227 & .002 & .097 & .404 & \\
\hline
\end{tabular}

Biochemical Analysis:

\section{Liver function test}

Among the Nosocomial Infection, $60 \%$ of the patients have raised ALT level, increased bilirubin (26.7\%), while $13.3 \%$ have raised ALP; however, a nonsignificant correlation was observed, as shown in table 3.4.

Table 3.4. Liver Functional test in culture-confirmed Nosocomial Infection 


\begin{tabular}{|lcclll|}
\hline Characteristics & T-value & P-value & \multicolumn{2}{l}{ 95\% Confidence interval } & R-Square \\
\cline { 3 - 6 } & & & Lower Boundries & Upper Boundries & 0.006 \\
Total Billirubin & .406 & .686 & -.185 & .280 & \\
\cline { 1 - 5 } ALT & .497 & .620 & -.142 & .237 & \\
\hline ALP & -.513 & .609 & -.370 & .218 \\
\hline
\end{tabular}

\section{Renal functional test}

The renal functional test analysis of culture-confirmed nosocomial patient's shows abnormal level of urea (33.3\%) $(P=0.002,95 \% \mathrm{Cl} .255-1.120, \mathrm{R}=0.119)$ while (46.7\%) Creatinine ( $P=0.00,95 \% \mathrm{Cl}-1.227-.392, \mathrm{R}=0.119)$ both were statistically significant as shown in the table 3.5 .

\section{Table 3.5. Correlation of Renal functional tests with Nosocomial Infection}

\begin{tabular}{|lcclll|}
\hline Characteristics & T-value & P-value & \multicolumn{2}{l}{ 95\% Confidence interval } & R-square \\
\cline { 5 - 6 } & & & Lower Boundries & Upper Boundries & 0.119 \\
Urea & 3.149 & .002 & .255 & 1.120 & \\
Creatinin & -3.843 & .000 & -1.227 & -.392 & \\
\hline
\end{tabular}

\section{Electrolytes Analysis}

Among the electrolytes analysis, Hypernatremia (26.7\%) ( $\mathrm{P}=0.000,95 \% \mathrm{Cl}-.491-.227, \mathrm{R}=0.703)$ were significant, while hyperchloremia (20\%) and Hypokalemia (6.7\%) were in-significant as shown in table 3.6.

Table 3.6. Electrolytes Analysis of culture-confirmed Nosocomial Infection patients

\begin{tabular}{|lccccc|}
\hline Characteristics & T-value & P-value & \multicolumn{2}{c|}{ 95\% Confidence Interval } & R-Square \\
\cline { 3 - 5 } & & & Lower boundries & Upper boundries & \multirow{2}{*}{0.703} \\
Hypokalemia & .582 & .562 & -.190 & .348 \\
Hyperchloremia & -.546 & .586 & -.248 & .141 \\
Hyponatremia & -.315 & .753 & -.576 & .418 \\
Hypochloremia & .682 & .497 & -.174 & .356 \\
Hypernatremia & -5.375 & .000 & -.491 & -.227 \\
\hline
\end{tabular}

\section{Microbial analysis and prevalence of nosocomial Infection}

A total of 30/120 (25\%) of all ICU admitted nosocomial-suspected patients were culture-confirmed, and 06 bacterial pathogens were isolated, consisting of $5 / 6$ (83.3\%) gram-negative bacteria. UTI was more frequently found (36.6\%), followed by bloodstream (26.6\%). Among gram-negative isolates, Klebsiella Pneumonia (40\%) was most commonly isolated, followed by Klebsiella oxytoca (13.3\%); however, MRSA (16.6\%) were the only gram-positive isolate.

MRSA (50\%) was the most frequent isolate followed by P.auroginosa (25\%) found in surgical site infection, while Klebsiella oxytoca (27.7\%) followed by $18.18 \%$ of Serratia liquefaciens and Serratia marcescens each was isolated from UTI. Klebsiella pneumonia (100\%) was the only bacterial isolate found in respiratory tract infection. Among bloodstream infections, Klebsiella pneumonia (37.5\%) was the most frequent isolate, followed by $25 \%$ of P.auroginosa and S.aureus each, as shown in the table 3.7.

Table 3.7. Distribution of bacterial isolates collected from patients of Nososcomial infection admitted to ICU of District Headquarter Hospital Rawalpindi, Pakistan, January 2019 to December 2020 


\begin{tabular}{|c|c|c|c|c|c|}
\hline Bacterial isolates & Surgical site no. (\%) & Urinary tract no. (\%) & Respiratory tract no. (\%) & Bloodstream no. (\%) & Total (\%) \\
\hline Klebsiella pneumonia & $1(25 \%)$ & $1(9.09 \%)$ & $7(100 \%)$ & $3 / 8(37.5 \%)$ & $12(40 \%)$ \\
\hline Klebsiella oxytoca & $0(0)$ & $3(27.27 \%)$ & $0(0)$ & $1(12.5 \%)$ & $4(13.3 \%)$ \\
\hline Serriatia liquefaciens & $0(0)$ & $2(18.18 \%)$ & $0(0)$ & $0 / 8(0)$ & $2(6.6 \%)$ \\
\hline Pseudomonase auroginosa & $1(25 \%)$ & $0(0)$ & $0(0)$ & $2 / 8(25 \%)$ & $3(10 \%)$ \\
\hline Serriatia marcescens & $0(0)$ & $2(18.18 \%)$ & $0(0)$ & $0 / 8(0)$ & $2(6.6 \%)$ \\
\hline Proteus spp & $0(0)$ & $2(18.18 \%)$ & $0(0)$ & $0(0)$ & $2(6.6 \%)$ \\
\hline S. aureus & $2(50 \%)$ & $1(9.09 \%)$ & $0(0)$ & $2(25 \%)$ & $5(16.6 \%)$ \\
\hline Total & $4(13.3 \%)$ & $11(36.6 \%)$ & $7(23.3 \%)$ & $8(26.6 \%)$ & $30(100 \%)$ \\
\hline
\end{tabular}

Antimicrobial Susceptibility Pattern.

Out of all collected isolates, $100 \%$ sensitivity towards imipenem was observed by Klebsiella pneumonia, Serratia liquefaciens, Proteus spp, while $75 \%$ by $K$. oxytoca. Besides imipenem, the sensitivity of Serratia marcescens towards ceftriaxone and amikacin were also observed. $100 \%$ of Serratia marcescens isolates showed sensitivity towards ceftriaxone and amikacin. Proteus spp were found sensitive towards amikacin and gentamycin. The majority of the gram-negative isolates were found resistant towards Amoxicillin + Clavulanic acid, Trimethoprim/sulfamethoxazole, cefoxitin, Levofloxacin, Norfloxacin, and linezolid, as shown in table 3.8. [Supplementary Figures 3.1, 3.2, 3.3]

Table 3.8. Antibiogram analysis of the entire bacterial agents isolated from Nosocomial Patients at District Headquarter Hospital Rawalpindi, Pakistan, January 2019 to December 2020.

\begin{tabular}{|c|c|c|c|c|c|c|c|c|c|c|c|c|c|}
\hline \multirow{2}{*}{$\begin{array}{l}\text { Microbial } \\
\text { isolates }\end{array}$} & \multirow[t]{2}{*}{ Positive } & \multirow[t]{2}{*}{ Pattern } & \multicolumn{11}{|c|}{ Antimicrobial susceptibility no (\%) } \\
\hline & & & AUG3+AMC30 & CTX & CAZ & CFM & CRO & FOX & zox & VA & AK & $\mathrm{CN}$ & $T$ \\
\hline \multirow{3}{*}{$\begin{array}{l}\text { K. } \\
\text { pneumoniae }\end{array}$} & \multirow[t]{3}{*}{12} & $\mathbf{R}$ & $12(100)$ & $12(1000$ & $12(100)$ & $9(75)$ & 11(91.6) & $12(100)$ & 10(85) & 10(85) & 10(85) & 10(85) & 1 \\
\hline & & $\mathrm{S}$ & 0 & 0 & 0 & 0 & $1(8.3)$ & 0 & $2(15)$ & $2(15)$ & $2(15)$ & $2(15)$ & 2 \\
\hline & & I & 0 & & 0 & $3(25)$ & 0 & 0 & 0 & 0 & 0 & 0 & 0 \\
\hline \multirow[t]{3}{*}{ K. oxytoca } & \multirow[t]{3}{*}{4} & $\mathbf{R}$ & $4(100)$ & $4(100)$ & $3(75)$ & $4(100)$ & $4(100)$ & $4(100)$ & $4(100)$ & $4(100)$ & $2(50)$ & $3(75)$ & 3 \\
\hline & & $S$ & 0 & 0 & 0 & 0 & 0 & 0 & 0 & 0 & $2(50)$ & $1(25)$ & 1 \\
\hline & & I & 0 & 0 & $1(25)$ & 0 & 0 & 0 & 0 & 0 & 0 & 0 & 0 \\
\hline \multirow{3}{*}{$\begin{array}{l}\text { Serriata } \\
\text { liquefaciens }\end{array}$} & \multirow[t]{3}{*}{2} & $\mathbf{R}$ & $2(100)$ & $2(100)$ & $2(100)$ & $2(100)$ & $2(100)$ & $2(100)$ & $2(100)$ & $2(100)$ & 0 & $1(50)$ & 2 \\
\hline & & $s$ & 0 & 0 & 0 & 0 & 0 & 0 & 0 & 0 & $2(100)$ & 0 & 0 \\
\hline & & I & 0 & 0 & 0 & 0 & 0 & 0 & 0 & 0 & 0 & $1(50)$ & 0 \\
\hline \multirow{3}{*}{$\begin{array}{l}\text { P. } \\
\text { aurigonosa }\end{array}$} & \multirow[t]{3}{*}{3} & $\mathbf{R}$ & $3(100)$ & $3(100)$ & $3(100)$ & $3(100)$ & $2(66.6)$ & $3(100)$ & $3(100)$ & 1(33.3) & $1(33.3)$ & $2(66.6))$ & 3 \\
\hline & & $s$ & 0 & 0 & 0 & 0 & $1(33.3)$ & 0 & 0 & $2(66.6)$ & $\begin{array}{l}2 \\
(66.6)\end{array}$ & & 0 \\
\hline & & I & 0 & 0 & 0 & 0 & 0 & 0 & 0 & 0 & 0 & 1(33.3) & 0 \\
\hline \multirow[t]{3}{*}{ MRSA } & \multirow[t]{3}{*}{5} & $\mathbf{R}$ & $4(80)$ & $5(100)$ & $5(100)$ & $4(80)$ & $3(60)$ & $5(100)$ & $4(80)$ & $3(80)$ & $2(40)$ & $4(80)$ & 5 \\
\hline & & $s$ & 0 & 0 & 0 & 0 & $2(40)$ & 0 & 0 & $2(40)$ & $2(40)$ & 0 & 0 \\
\hline & & I & $1(20)$ & 0 & 0 & $1(20)$ & 0 & 0 & $1(20)$ & 0 & $1(20)$ & $1(20)$ & 0 \\
\hline \multirow{3}{*}{$\begin{array}{l}\text { Serrriatia } \\
\text { marcescens }\end{array}$} & \multirow[t]{3}{*}{2} & $\mathbf{R}$ & $2(100)$ & $2(100)$ & $2(100)$ & $2(100)$ & 0 & $2(100)$ & 1(50) & $1(50)$ & 0 & $2(100)$ & 1 \\
\hline & & $s$ & 0 & 0 & 0 & 0 & $2(100)$ & 0 & 0 & $1(50$ & $2(100)$ & 0 & 1 \\
\hline & & I & 0 & 0 & 0 & 0 & 0 & 0 & $1(50)$ & 0 & 0 & 0 & 0 \\
\hline \multirow[t]{3}{*}{ Proteus spp } & \multirow[t]{3}{*}{2} & $\mathbf{R}$ & $1(50)$ & $2(100)$ & $2(100)$ & $2(100)$ & 0 & 0 & $2(100)$ & $2(100)$ & 0 & 0 & 2 \\
\hline & & $S$ & 0 & 0 & 0 & 0 & $1(50)$ & 0 & 0 & 0 & $2(100)$ & $2(100)$ & 0 \\
\hline & & I & $1(50)$ & 0 & 0 & 0 & $1(50)$ & $2(100)$ & 0 & 0 & 0 & 0 & 0 \\
\hline
\end{tabular}

S: sensitive; R: resistance; I: Intermediate; CIP: ciprofloxacin; CRO: ceftriaxone; CAZ: ceftazidime; IPM: imipenem; LZD: linezolid; FOX: Cefoxitin; CFM: Cefixime; CTX: Cefotaxime; AK: Amikacin; CN: Gentamicin; TOB: Tobramycin; VA: Vancomycin; Lev: Levofloxacin; Ofx: Ofloxacin; Nor: Norfloxacin; Sxt:

Trimothoprim/sulfamethoxazole; MXF: Moxifloxacin; AUG3+AMC30: Amoxicillin + Clavulanic acid; ZOX: ceftizoxime 
Trimethoprim/sulfamethoxazole was a highly effective antibiotic against the gram-positive isolates (MRSA); however, all of them were resistant towards linezolid, imipenem, and Cefotaxime, etc. as shown in table 3.8. [Supplementary Figures 3.4].

\section{Discussion}

Nosocomial Infections (NCls) or Hospital Acquired Infections (HAls) are the leading cause of public health issues worldwide with variation in prevalence rates (26). The main strategies for managing these infections are the source and understanding of the conditions, the pathogens involved in HAl, and its risk factors (27).

The majority of the ICU patients experiences nosocomial bloodstream infections, total leukocytes count (TLC) and C-reactive protein (CRP) play a pivotal rule in the diagnosis of these infections (28-31). The current study observed that $60 \%$ of the nosocomial patients have leukocytosis that describes the possible important role of leukocytosis in nosocomial infection, as describes earlier (28-31). Lymphopenia and risk of infection are poorly studied; however, according to a report, there is a 2.4 -fold increased risk of lower respiratory tract infection and urinary tract infection with lymphopenia (32). So for another study at ICU reports that lymphopenia at admittance was associated with a 1.6-fold increased risk of infection(33). Similarly, in the general population, lymphopenia was associated with an increased risk of hospitalization due to conditions like sepsis, endocarditis, diarrheal disease, pneumonia, urinary tract infection, and skin infection (34). In the literature (35-37), it is well established that, in many cases, febrile neutropenic patients have bacteremia without any specific focus (37). Although most infections of neutropenic patients' are only clinically documented (37-39). The above-mentioned reports assist our current study, where we found $73.3 \%$ of the nosocomial patients with lymphopenia. However, discrepancies between the findings in the present and former studies ( $32,40,41)$ may be due to our study design that includes only nosocomial patients. The current study found Neutrocytosis in $73.3 \%$ of nosocomial infected patients as Neutrocytosis is frequently observed in the circulation and tissues during bacterial or fungal infections (42). The Neutrocytosis in the current study may be due to their important role during fungal and extracellular bacterial infections where they promote bacterial clearance through phagocytosis, production of reactive oxygen and nitrogen species (ROS/RNS), neutrophil extracellular trap (NET) formation, and production of pro-inflammatory cytokin(43, 44).

According to the current study, $33.3 \%$ of the nosocomial patients have thrombocytopenia, $12 \%$ have abnormal PT. In comparison, $8 \%$ have abnormal APTT; likewise, prolonged PT of $63.3 \%$ was observed in neonatal septicemia during nosocomial infection, more frequently among gram-negative infected patients (45). The deviation of our results may be because of different pathogenic microbes in the study may complicate infections by consumption coagulopathy (46), as well as the difference in the exposure to endotoxins, which may be attributed to the direct action of the endotoxins on endothelial cells or maybe an indirect result of the production of interleukin 1 or tumor necrosis factor $(47,48)$.

The liver is one of the vital organs exposed to both hepatotropic and non-hepatotropic viruses and bacteria through the portal and systemic circulation and causes liver injury, either direct invasion or indirect cytokines and toxin production $(49,50)$. However, patients of Pneumococcal pneumonia and lobar pneumonia caused by one of the bacteria among S. pneumonia, P. aeruginosa, $S$. aureus, or Haemophilus influenza sometimes show elevated concentrations of bilirubin and Serum glutamic pyruvic transaminase/serum aminotransferases (SGPT/ALT) (51). Similar reports of elevated ALT/SGPT and bilirubin have been reported in typhoid fever caused by Salmonella typhi and gastroenteritis caused by nontyphoidal Salmonella (most commonly $S$. enteritidis and $S$. Typhimurium) (52). Consistently in the current study, an elevated level of SGPT/ALT, Bilirubin, and ALP among $60 \%, 26.7 \%$, and $13.3 \%$ were found respectively among nosocomial patients. The changes in liver function tests in case of nosocomial infection are may be due to hepatic injury caused by nosocomial pathogens. So for in case of liver dysfunction during systemic disease, proper microbial examination, and sufficient knowledge about non-hepatotropic agents are necessary (49).

The said study finds that among nosocomial patients, 33.3\% have an abnormal level of Urea. In comparison, $46.7 \%$ have an uncommon level of Creatinine; however, to our knowledge, there are no data to suggest whether or not the association of renal function test and nosocomial infection. Some previous studies report the higher risk of disease caused by MDROs, MRSA and VRE, in patients undergoing hemodialysis $(53,54)$. The renal function test increase may be due to the kidneys complication, either direct kidney injuries or immune-mediated injuries caused by all viruses, bacteria, mycobacteria, fungus, and protozoa (55) founds in nosocomial infections.

The current study reports that upon electrolytes analysis of nosocomial patients, $26.7 \%$ have Hypernatremia, $20 \%$ have hyperchloremia, while $6.7 \%$ have Hypokalemia. The change in various electrolytes might be due to the excessive use of antibiotics, which are directly proportional to Nls. Their adverse effects may be responsible for electrolyte abnormalities such as aminoglycosides, amphotericin B, trimethoprim, and tetracycline cause electrolyte disturbance (5658).

The prevalence of culture-confirmed nosocomial infection in the current study was 25\%, which is lower than other reports of $29.13 \%$ by Shaikh et al. (59), $27.03 \%$ by Noor et al.(60) from Pakistan, 35.8\% from Ethiopia (61), however higher than that of Rabat, Morocco (10.3\%) by (62), 6.9\% in Eastern Ethiopia by (26), $0.3 \%$ from ambarene, Gabon by (63), and $1.03 \%$ from Mazandaran, India (64). The results may be due to many factors, like the difference in patient selection criteria, the case mix, ICU type, length of stay, device utilization rate, and discharge criteria $(65,66)$. The current study shows that the ratio of gramnegative vs. gram-positive isolates was $83.3 \%: 16.6 \%$, similar to other studies that most nosocomial infections occurring in the ICU are due to Gram-negative bacteria $(19,67)$. The precise pattern of causative organisms, whether bacterial or fungal, varies across countries and between ICUs according to patient case mix, infection site, antibiotic protocols, infection control practice, and local ecology and resistance patterns (28).

The current study shows that SSI contributes $13.3 \%$ of all infections, which was higher compared to the survey from Ethiopia (10.9\%) (68), Iran (8.6\%) (69) while lower as compared to (31.5\%) reported by Tolera et al.(26). The prevalence of BSIs $(26.6 \%)$ in this study was relatively comparable with the findings of (22.7\%) by Shaikh et al. (59) from Pakistan and Ethiopia (20.8\%) (61) while much higher compared with the study performed at Bahirdar (2.4\%) (68). The current study reported $36.6 \%$ of the nosocomial infection was UTI which is higher than $9.03 \%$ and $9.4 \%$ reported by $(70,71)$ respectively. The discrepancy in the results may be due to the difference in the frequency of NSI in various developed and developing countries (72).

Page $7 / 12$ 
The current study found that the most frequent bacteria causing Nls were K. pneumonia (40\%) and S. aureus (16.6\%), consistent with other findings (61, 64 , 73). The current study shows that imipenem was the most effective antibiotic against gram-negative isolates of Klebsiella pneumonia, K. oxytoca, Proteus spp, Serratia liquefaciens Serratia marcescens. Simultaneously, the majority of the resistance was found against Amoxicillin + Clavulanic acid, Trimethoprim/sulfamethoxazole, cefoxitin, Levofloxacin, Norfloxacin, and linezolid. Similar supporting results of sensitivity for Klebsiella pneumonia and Klebsiella oxytoca were reported (74-76). According to a study, K.pneumoniae was found resistant to all $\beta$-lactams and meropenem however susceptible to imipenem by (77) and resistance to all ß-lactams, including meropenem except imipenem was found by (78-80). A similar consistent result of sensitivity against Proteus spp was found elsewhere $(81,82)$. Meropenem and imipenem were the potent antimicrobials against Proteus spp. $(83,84)$, in contrast to the resistance against imipenem and aztreonam by (85). Resistance rates were noted highest against ceftriaxone, ceftazidime, and piperacillin/tazobactam (86). According to a study, the isolated Serratia strain was sensitive towards imipenem, cefotetan, gentamicin, etc. (87), supporting the reported result of susceptibility to imipenem, meropenem, and amikacin, etc. (88). The sensitivity of $S$. marcescens was detected for imipenem, meropenem, and ceftazidime, etc. (89). The resistance of $S$. marcescens towards fluoroquinolones and third-generation cephalosporins was found by (88, 90-97).

Methicillin-Resistant Staphylococcus aureus (MRSA) was the only gram-positive isolate found in the study, highly sensitive towards Trimethoprim/sulfamethoxazole while resistant towards linezolid, Imipenem, and Cefotaxime, etc. Consistently similar reports from various countries show that around $90 \%$ of S. aureus isolated from nosocomial infections and community remain sensitive to Trimethoprim/sulfamethoxazole from the USA (98100), Europe, Israel, and Turkey (101-103), Japan (104), Canada (105-108). A study reports higher susceptibility to amoxicillin + clavulanic acid, Doxycycline and Gentamicin, etc. (109). In contrast to the above reports, 30\% of hospital-acquired MRSA in Australia, 19\% in sub-Saharan Africa (110), and $85 \%$ from India $(111,112)$ were resistant towards Trimethoprim/sulfamethoxazole. Various reports observed resistance of s.aureus towards ampicillin and penicillin, rifampicin and clindamycin, oxacillin and erythromycin (108), Azithromycin, Ceftriaxone, Cefixime and Penicillin (109), Gentamycin, Erythromycin, Levofloxacin and Tetracycline (113). The divergence in the findings could be attributed to the mechanism of resistance like the permeability barrier, efflux pumps, mutational or recombinational changes in the target enzymes and acquired resistance by drug-resistant target enzymes in various antibiotics and alteration of the target with decreased affinity for the antibiotics (114).

\section{Conclusion}

The current study revealed that nosocomial infection is still prevalent in our hospital environment and the leading cause of drug resistance and dysfunctions of various factors like WBCs, LFTs, RFTs, electrolytes, coagulation factors and anemia, which can lead to morbidity and mortality.

\section{Abbreviations}

Nosocomial Infections, HCAl: Health care Associated Infections, WBCs: White Blood cells, UTI: Urinary tract infection, MRSA: Methicilin Resistant Staphylococcus aureus

\section{Declarations}

On behalf of all the co-authors, I am submitting the enclosed manuscript for potential publication only in Journal of Antimicrobial Resistance and Infection Control. I attest that this paper has not been published in whole elsewhere and is prepared following the instructions to authors. All authors have contributed to this manuscript, reviewed and approved the current form of the manuscript to be submitted.

\section{- Ethics approval and consent to participate}

The ethical review committee of Rawalpindi Medical University approved the current study (S/No. 12-13/RMU-2019). The patients were informed about the research study before sample collection. A written consent form was filled from the entire patients.

\section{- Consent for publication}

All the patients were informed for the publication of the current study

\section{- Availability of data and materials}

The corresponding author will provide the data and information on the currents study on reasonable requests.

- Competing interests

JK, IA, NB, AK, AS, SA, MS, ANK, IA, SS, AA, HK, and IA declare that they have no competing interests.

- Funding

Not applicable

\section{- Authors' contributions}

All authors have read and approved the manuscript. JK, NB designed the study. IA experimented. AK, SA, AS, SS, IA were major contributors in the writing of the manuscript. SA, ANK performed the statistical analysis and figure of the schoolroom. AA, HK, IA reviewed the final manuscript. 
We acknowledge HEC (Higher Education Commission), COMWAVE Institute Islamabad and Sarhad University Peshawar for technical and funding support for the current study.

\section{References}

1. Collins AS. Preventing health care-associated infections. Patient safety and quality: an evidence-based handbook for nurses: Agency for Healthcare Research and Quality (US); 2008.

2. Revelas A. Healthcare-associated infections: A public health problem. Nigerian medical joumal: journal of the Nigeria Medical Association. 2012;53(2):59.

3. Nazir A, Kadri S. An overview of hospital acquired infections and the role of the microbiology laboratory. Int J Res Med Sci. 2014;2(1):21-7.

4. Giri PA, Kamble MG, Kasat VO, Phalke DB. Knowledge about hospital-acquired infections amongst nursing staff of tertiary care teaching hospital in rural western Maharashtra, India. International Joumal of Medical Science and Public Health. 2016;5(05):839.

5. Khan HA, Baig FK, Mehboob R. Nosocomial infections: Epidemiology, prevention, control and surveillance. Asian Pacific Joumal of Tropical Biomedicine. 2017;7(5):478-82.

6. Pittet D, Allegranzi B, Storr J, Nejad SB, Dziekan G, Leotsakos A, et al. Infection control as a major World Health Organization priority for developing countries. Journal of Hospital Infection. 2008;68(4):285-92.

7. Organization WH. WHO guidelines on hand hygiene in health care: first global patient safety challenge clean care is safer care: World Health Organization; 2009.

8. Irwin RS, Rippe JM. Irwin and Rippe's intensive care medicine: Lippincott Williams \& Wilkins; 2008.

9. Dasgupta S, Das S, Chawan NS, Hazra A. Nosocomial infections in the intensive care unit: Incidence, risk factors, outcome and associated pathogens in a public tertiary teaching hospital of Eastern India. Indian journal of critical care medicine: peer-reviewed, official publication of Indian Society of Critical Care Medicine. 2015;19(1):14.

10. Abdel-Fattah MM. Surveillance of nosocomial infections at a Saudi Arabian military hospital for a one-year period. GMS German Medical Science. 2005;3.

11. Sievert DM, Ricks P, Edwards JR, Schneider A, Patel J, Srinivasan A, et al. Antimicrobial-resistant pathogens associated with healthcare-associated infections: summary of data reported to the National Healthcare Safety Network at the Centers for Disease Control and Prevention, 2009-2010. Infection control and hospital epidemiology. 2013;34(1):1-14.

12. Hidron Al, Edwards JR, Patel J, Horan TC, Sievert DM, Pollock DA, et al. Antimicrobial-resistant pathogens associated with healthcare-associated infections: annual summary of data reported to the National Healthcare Safety Network at the Centers for Disease Control and Prevention, $2006-2007$. Infection control and hospital epidemiology. 2008;29(11):996-1011.

13. Weiner L, Webb A, Limbago B, Dudeck M, Patel J, Kallen A. 284 JR Edwards, and DM Sievert. 2016. Antimicrobial-resistant pathogens 285 associated with healthcare-associated infections: Summary of data reported to the 286 National Healthcare Safety Network at the Centers for Disease Control and 287 Prevention, 2011-2014. Infect Control Hosp Epidemiol.37:1288-301.

14. Craig W. Pharmacodynamics of antimicrobial agents as a basis for determining dosage regimens. European Journal of Clinical Microbiology and Infectious Diseases. 1993;12(1):S6-S8.

15. Vogelman B, Craig WA. Kinetics of antimicrobial activity. The Journal of pediatrics. 1986;108(5):835-40.

16. Estes $L$, editor Review of pharmacokinetics and pharmacodynamics of antimicrobial agents. Mayo Clinic Proceedings; 1998: Elsevier.

17. Pankey GA, Sabath L. Clinical relevance of bacteriostatic versus bactericidal mechanisms of action in the treatment of Gram-positive bacterial infections. Clinical infectious diseases. 2004;38(6):864-70.

18. Mehrad B, Clark NM, Zhanel GG, Lynch III JP. Antimicrobial resistance in hospital-acquired gram-negative bacterial infections. Chest. 2015;147(5):1413-21.

19. Vincent J-L, Rello J, Marshall J, Silva E, Anzueto A, Martin CD, et al. International study of the prevalence and outcomes of infection in intensive care units. Jama. 2009;302(21):2323-9.

20. Laxminarayan R, Duse A, Wattal C, Zaidi AK, Wertheim HF, Sumpradit N, et al. Antibiotic resistance-the need for global solutions. The Lancet infectious diseases. 2013;13(12):1057-98.

21. Vasudevan A, Memon BI, Mukhopadhyay A, Li J, Tambyah PA. The costs of nosocomial resistant gram negative intensive care unit infections among patients with the systemic inflammatory response syndrome-a propensity matched case control study. Antimicrobial resistance and infection control. 2015;4(1):3.

22. Morales E, Cots F, Sala M, Comas M, Belvis F, Riu M, et al. Hospital costs of nosocomial multi-drug resistant Pseudomonas aeruginosa acquisition. BMC Health Services Research. 2012;12(1):122.

23. Horan TC, Andrus M, Dudeck MA. CDC/NHSN surveillance definition of health care-associated infection and criteria for specific types of infections in the acute care setting. American journal of infection control. 2008;36(5):309-32.

24. Clinical and Laboratory Standards Institute (CLSI) PSfAST, CLSI, Wayne, PA, USA, 2015.

25. Magiorakos A-P, Srinivasan A, Carey R, Carmeli Y, Falagas M, Giske C, et al. Multidrug-resistant, extensively drug-resistant and pandrug-resistant bacteria: an international expert proposal for interim standard definitions for acquired resistance. Clinical microbiology and infection. $2012 ; 18(3): 268-81$.

26. Tolera M, Abate D, Dheresa M, Marami D. Bacterial nosocomial infections and antimicrobial susceptibility pattern among patients admitted at hiwot fana specialized university hospital, Eastem Ethiopia. Advances in medicine. 2018;2018.

27. Haque M, Sartelli M, McKimm J, Bakar MA. Health care-associated infections-an overview. Infection and drug resistance. $2018 ; 11: 2321$.

Page $9 / 12$ 
28. Vincent J-L. Microbial resistance: lessons from the EPIC study. Intensive care medicine. 2000;26(1):S003-S8.

29. Povoa P, Coelho L, Almeida E, Fernandes A, Mealha R, Moreira P, et al. C-reactive protein as a marker of infection in critically ill patients. Clinical microbiology and infection. 2005;11(2):101-8.

30. Sprung CL, Sakr Y, Vincent J-L, Le Gall J-R, Reinhart K, Ranieri VM, et al. An evaluation of systemic inflammatory response syndrome signs in the Sepsis Occurrence In Acutely III Patients (SOAP) study. Intensive care medicine. 2006;32(3):421-7.

31. Spapen H, Hachimi-Idrissi S, Come L, Huyghens L. Diagnostic markers of sepsis in the emergency department. Acta Clinica Belgica. $2006 ; 61(3): 138-42$.

32. Chang C-J, Chen L-Y, Liu L-K, Lin M-H, Peng L-N, Chen L-K. Lymphopenia and poor performance status as major predictors for infections among residents in long-term care facilities (LTCFs): a prospective cohort study. Archives of Gerontology and Geriatrics. 2014;58(3):440-5.

33. Adrie C, Lugosi M, Sonneville R, Souweine B, Ruckly S, Cartier J-C, et al. Persistent lymphopenia is a risk factor for ICU-acquired infections and for death in ICU patients with sustained hypotension at admission. Annals of intensive care. 2017;7(1):30.

34. Warny M, Helby J, Nordestgaard BG, Birgens H, Bojesen SE. Lymphopenia and risk of infection and infection-related death in 98,344 individuals from a prospective Danish population-based study. PLoS medicine. 2018;15(11):e1002685.

35. Billote KP, Mendoza M, Baylon HG. Infections in febrile neutropenia and possible prognostic factors associated with mortality. Philip J Microbiol Infect Dis. 1997;26(2):55-9.

36. Bodey GP. Fever and neutropenia: the early years. Journal of Antimicrobial Chemotherapy. 2009;63(suppl_1):i3-i13.

37. Wisplinghoff H, Cornely OA, Moser S, Bethe U, Stützer H, Salzberger B, et al. Outcomes of nosocomial bloodstream infections in adult neutropenic patients: a prospective cohort and matched case-control study. Infection Control \& Hospital Epidemiology. 2003;24(12):905-11.

38. Freifeld AG, Bow EJ, Sepkowitz KA, Boeckh MJ, Ito JI, Mullen CA, et al. Clinical practice guideline for the use of antimicrobial agents in neutropenic patients with cancer: 2010 update by the Infectious Diseases Society of America. Clinical infectious diseases. 2011;52(4):e56-e93.

39. Ramphal R. Changes in the etiology of bacteremia in febrile neutropenic patients and the susceptibilities of the currently isolated pathogens. Clinical infectious diseases. 2004;39(Supplement_1):S25-S31.

40. Merayo-Chalico J, Gomez-Martin D, Pineirua-Menendez A, Santana-De Anda K, Alcocer-Varela J. Lymphopenia as risk factor for development of severe infections in patients with systemic lupus erythematosus: a case-control study. QJM: An International Journal of Medicine. 2013;106(5):451-7.

41. $\mathrm{Ng} \mathrm{W}$, Chu C, Wu A, Cheng V, Yuen $\mathrm{K}$. Lymphopenia at presentation is associated with increased risk of infections in patients with systemic lupus erythematosus. Qjm. 2006;99(1):37-47.

42. Lekstrom-Himes JA, Gallin Jl. Immunodeficiency diseases caused by defects in phagocytes. New England Journal of Medicine. 2000;343(23):1703-14.

43. Mócsai A. Diverse novel functions of neutrophils in immunity, inflammation, and beyond. Journal of Experimental Medicine. 2013;210(7):1283-99.

44. Nauseef WM, Borregaard N. Neutrophils at work. Nature immunology. 2014;15(7):602-11.

45. Shittu Bashirat T, Shittu Mujeeb O, Oluremi Adeolu S, Orisadare Olayiwola P, Osemeke J, Bello Lateef A. Thrombocytopenia and Prolonged Prothrombin Time in Neonatal Septicemia.

46. Saving KL. Disseminated intravascular coagulation: diagnosis and management. The Indian Journal of Pediatrics. 1987;54(3):391-402.

47. van Deventer S, Buller H, ten Cate J, Aarden L, Hack C, Sturk A. Experimental endotoxemia in humans: analysis of cytokine release. 2011.

48. Kruithof E, Calandra T, Pralong G, Heumann D, Gerain J, Baumgartner J, et al. Evolution of plasminogen activator inhibitor type 1 in patients with septic shock-correlation with cytokine concentrations. Fibrinolysis. 1993;7(2):117-21.

49. Minemura M, Tajiri K, Shimizu Y. Liver involvement in systemic infection. World journal of hepatology. 2014;6(9):632.

50. Szabo G, Romics Jr L, Frendl G. Liver in sepsis and systemic inflammatory response syndrome. Clinics in liver disease. 2002;6(4):1045-66, X.

51. Radford A, Rhodes F, Matz L. The association of jaundice with lobar pneumonia in the territory of Papua and New Guinea. Medical Journal of Australia. 1967;2(15):678-81.

52. Gitlin N. The liver and systemic disease: Churchill Livingstone; 1997.

53. Crowley L, Wilson J, Guy R, Pitcher D, Fluck R. Epidemiology of Staphylococcus Aureus bacteraemia amongst patients receiving dialysis for established renal failure in England in 2009 to 2011: a joint report from the health Protection Agency and the UK Renal Registry. Nephron Clinical practice. 2012;120(Suppl. 1):c233-c45.

54. Zacharioudakis IM, Zervou FN, Ziakas PD, Rice LB, Mylonakis E. Vancomycin-resistant enterococci colonization among dialysis patients: A meta-analysis of prevalence, risk factors, and significance. American Journal of Kidney Diseases. 2015;65(1):88-97.

55. Prasad N, Patel MR. Infection-induced kidney diseases. Frontiers in Medicine. 2018;5:327.

56. Kim YW. Antimicrobial-induced electrolyte and acid-base disturbances. Electrolyte \& Blood Pressure. 2007;5(2):111-5.

57. Inweregbu K, Dave J, Pittard A. Nosocomial infections. Continuing Education in Anaesthesia, Critical Care \& Pain. 2005;5(1):14-7.

58. HASHEMI SH, Mamani M, JAMAL OS, Niayesh A. Nosocomial bacterial infections and their antimicrobial resistance patterns in university hospitals of Hamedan, Iran. 2010.

59. Shaikh JM, Devrajani BR, Shah S, Akhund T, Bibi I. Frequency, pattern and etiology of nosocomial infection in intensive care unit: an experience at a tertiary care hospital. J Ayub Med Coll Abbottabad. 2008;20(4):37-40.

60. Noor N, Alina Z, Niazi A, Kamran M, Naseer F. Determination of current trend of nosocomial infections in ICU of Benazir Bhutto Hospital Rawalpindi, Pakistan.

61. Endalafer N, Gebre-Selassie S, Kotiso B. Nosocomial bacterial infections in a tertiary hospital in Ethiopia. Joumal of Infection Prevention. 2011;12(1):3843. 
62. Razine R, Azzouzi A, Barkat A, Khoudri I, Hassouni F, Chefchaouni AC, et al. Prevalence of hospital-acquired infections in the university medical center of Rabat, Morocco. International archives of medicine. 2012;5(1):26.

63. Scherbaum M, Kösters K, Mürbeth RE, Ngoa UA, Kremsner PG, Lell B, et al. Incidence, pathogens and resistance patterns of nosocomial infections at a rural hospital in Gabon. BMC infectious diseases. 2014;14(1):124.

64. Davoudi AR, Najafi N, Shirazi MH, Ahangarkani F. Frequency of bacterial agents isolated from patients with nosocomial infection in teaching hospitals of Mazandaran University of Medical Sciences in 2012. Caspian journal of internal medicine. 2014;5(4):227.

65. Richards MJ, Edwards JR, Culver DH, Gaynes RP. Nosocomial infections in medical intensive care units in the United States. Critical care medicine. 1999;27(5):887-92.

66. Erbay H, Yalcin AN, Serin S, Turgut H, Tomatir E, Cetin B, et al. Nosocomial infections in intensive care unit in a Turkish university hospital: a 2-year survey. Intensive care medicine. 2003;29(9):1482-8.

67. Richards MJ, Edwards JR, Culver DH, Gaynes RP, System NNIS. Nosocomial infections in combined medical-surgical intensive care units in the United States. Infection Control \& Hospital Epidemiology. 2000;21(8):510-5.

68. Mulu W, Kibru G, Beyene G, Damtie M. Postoperative nosocomial infections and antimicrobial resistance pattern of bacteria isolates among patients admitted at Felege Hiwot Referral Hospital, Bahirdar, Ethiopia. Ethiopian journal of health sciences. 2012;22(1):7-18.

69. Tabatabaei SM, Pour FB, Osmani S. Epidemiology of hospital-acquired infections and related anti-microbial resistance pattems in a tertiary-care teaching hospital in Zahedan, Southeast Iran. International Joumal of Infection. 2015;2(4):3-8.

70. Kamat US, Fereirra A, Amonkar D, Motghare DD, Kulkarni MS. Epidemiology of hospital acquired urinary tract infections in a medical college hospital in Goa. Indian journal of urology: IJU: journal of the Urological Society of India. 2009;25(1):76.

71. Melaku S, Kibret M, Abera B, Gebre-Sellassie S. Antibiogram of nosocomial urinary tract infections in Felege Hiwot referral hospital, Ethiopia. African Health Sciences. 2012;12(2):134-9.

72. Nicastri E, Leone S. GUIDE TO INFECTION CONTROL IN THE HEALTHCARE SETTING Hospital-Acquired Urinary Tract Infection.

73. Shoaei S, Sali S, Yousefi H. Incidence and resistance patterns of nosocomial infections in labbafi nejad hospital admitted patients during $2012-2014$. Infection, Epidemiology and Microbiology. 2017;3(3):78-81.

74. Newman CD, editor Catheter-related bloodstream infections in the pediatric intensive care unit. Seminars in pediatric infectious diseases; 2006: Elsevier.

75. Ali FA, Ismael RM. Dissemination of Klebsiella pneumonia and Klebsiella oxytoca Harboring bla TEM genes isolated from different clinical samples in Erbil City. Diyala Journal of Medicine. 2017;12(2):40-51.

76. Feizabadi MM, Etemadi G, Yadegarinia D, Rahmati M, Shabanpoor S, Bokaei S. Antibiotic-resistance patterns and frequency of extended-spectrum blactamase-producing isolates of Klebsiella pneumoniae in Tehran. Medical science monitor. 2006;12(11):BR362-BR5.

77. Harino T, Kayama S, Kuwahara R, Kashiyama S, Shigemoto N, Onodera M, et al. Meropenem resistance in ISMRK not detected by rapid automated susceptibility testing system. Journal of Clinical Microbiology. 2013.

78. Tang H-J, Ku Y-H, Lee M-F, Chuang Y-C, Yu W-L. In vitro activity of imipenem and colistin against a carbapenem-resistant Klebsiella pneumoniae isolate coproducing SHV-31, CMY-2, and DHA-1. BioMed Research International. 2015;2015.

79. Cao VTB, Arlet G, Ericsson B-M, Tammelin A, Courvalin P, Lambert T. Emergence of imipenem resistance in Klebsiella pneumoniae owing to combination of plasmid-mediated CMY-4 and permeability alteration. Journal of Antimicrobial Chemotherapy. 2000;46(6):895-900.

80. Lomovskaya O, Sun D, Rubio-Aparicio D, Nelson K, Tsivkovski R, Griffith DC, et al. Vaborbactam: spectrum of beta-lactamase inhibition and impact of resistance mechanisms on activity in Enterobacteriaceae. Antimicrobial agents and chemotherapy. 2017;61(11).

81. Khorshidi A, Sharif A. Imipenem resistance among gram-negative and gram-positive bacteria in hospitalized patients. Iranian journal of public health. 2010;39(2):110.

82. Feglo PK, Gbedema SY, Quay SNA, Adu-Sarkodie Y, Opoku-Okrah C. Occurrence, species distribution and antibiotic resistance of Proteus isolates: A case study at the Komfo Anokye Teaching Hospital (KATH) in Ghana. Int J Pharm Sci Res. 2010;1(9):347-52.

83. García-Rodríguez JA, Fresnadillo Martínez MJ. Dynamics of nasopharyngeal colonization by potential respiratory pathogens. Joumal of Antimicrobial Chemotherapy. 2002;50(suppl_3):59-74.

84. Tsai C-H, Fordyce RE. Juvenile morphology in baleen whale phylogeny. Naturwissenschaften. 2014;101(9):765-9.

85. Sekowska A, Dénervaud V, Ashida H, Michoud K, Haas D, Yokota A, et al. Bacterial variations on the methionine salvage pathway. BMC microbiology. 2004;4(1):9.

86. Şimşek M. Some closed-form solutions for static, buckling, free and forced vibration of functionally graded (FG) nanobeams using nonlocal strain gradient theory. Composite Structures. 2019;224:111041.

87. Bozkurt A, Rosen A, Rosen H, Onaral B. A portable near infrared spectroscopy system for bedside monitoring of newbom brain. Biomedical engineering online. 2005;4(1):1-11.

88. Tıraş M. Ulaşımın yerleşmeye etkisine bir ömek" Pozantı". Türk Coğrafya Dergisi. 2002(38):121-31.

89. Pfaller M, Jones R, Messer S, Edmond M, Wenzel R. National surveillance of nosocomial blood stream infection due to Candida albicans: frequency of occurrence and antifungal susceptibility in the SCOPE Program. Diagnostic microbiology and infectious disease. 1998;31(1):327-32.

90. Mahlen SD. Serratia infections: from military experiments to current practice. Clinical microbiology reviews. 2011;24(4):755-91.

91. Lapenda J, Silva P, Vicalvi M, Sena K, Nascimento S. Antimicrobial activity of prodigiosin isolated from Serratia marcescens UFPEDA 398 . World Journal of Microbiology and Biotechnology. 2015;31(2):399-406. 
92. Gerc AJ, Song L, Challis GL, Stanley-Wall NR, Coulthurst SJ. The insect pathogen Serratia marcescens Db10 uses a hybrid non-ribosomal peptide synthetase-polyketide synthase to produce the antibiotic althiomycin. PloS one. 2012;7(9):e44673.

93. Bobenchik AM, Deak E, Hindler JA, Charlton CL, Humphries RM. Performance of Vitek 2 for antimicrobial susceptibility testing of Enterobacteriaceae with Vitek 2 (2009 FDA) and 2014 CLSI breakpoints. Joumal of clinical microbiology. 2015;53(3):816-23.

94. Yu W, Lin C, Wang D. Serratia marcescens bacteremia: clinical features and antimicrobial susceptibilities of the isolates. Journal of Microbiology, Immunology and Infection. 1998;31(3):171-9.

95. Marumo K, Nakamura Y, Togashi M. Epidemiological evaluation of Serratia marcescens isolates in one Japanese hospital during the two years from April 1997 to March 1999. Rinsho byori The Japanese Journal of Clinical Pathology. 2000;48(10):960-5.

96. Hsueh P-R, Liu Y-C, Yang D, Yan J-J, Wu T-L, Huang W-K, et al. Multicenter surveillance of antimicrobial resistance of major bacterial pathogens in intensive care units in 2000 in Taiwan. Microbial Drug Resistance. 2001;7(4):373-82.

97. Yang H-F, Cheng J, Hu L-F, Ye Y, Li J-B. Plasmid-mediated quinolone resistance in extended-spectrum- $\beta$-lactamase-and AmpC $\beta$-lactamase-producing Serratia marcescens in China. Antimicrobial agents and chemotherapy. 2012;56(8):4529-31.

98. Richter SS, Heilmann KP, Dohrn CL, Riahi F, Costello AJ, Kroeger JS, et al. Activity of ceftaroline and epidemiologic trends in Staphylococcus aureus isolates collected from 43 medical centers in the United States in 2009. Antimicrobial agents and chemotherapy. 2011;55(9):4154-60.

99. Wackett A, Nazdryn A, Spitzer E, Singer AJ. MRSA rates and antibiotic susceptibilities from skin and soft tissue cultures in a suburban ED. The Journal of emergency medicine. 2012;43(4):754-7.

100. Wood JB, Smith DB, Baker EH, Brecher SM, Gupta K. Has the emergence of community-associated methicillin-resistant Staphylococcus aureus increased trimethoprim-sulfamethoxazole use and resistance?: a 10-year time series analysis. Antimicrobial agents and chemotherapy. 2012;56(11):5655-60.

101. Farrell DJ, Flamm RK, Sader HS, Jones RN. Ceftobiprole activity against over 60,000 clinical bacterial pathogens isolated in Europe, Turkey, and Israel from 2005 to 2010. Antimicrobial agents and chemotherapy. 2014;58(7):3882-8.

102. Schaumburg F, Onwugamba FC, Akulenko R, Peters G, Mellmann A, Köck R, et al. A geospatial analysis of flies and the spread of antimicrobial resistant bacteria. International Journal of Medical Microbiology. 2016;306(7):566-71.

103. Harbarth S, Von Dach E, Pagani L, Macedo-Vinas M, Huttner B, Olearo F, et al. Randomized non-inferiority trial to compare trimethoprim/sulfamethoxazole plus rifampicin versus linezolid for the treatment of MRSA infection. Journal of Antimicrobial Chemotherapy. 2015;70(1):264-72.

104. Hanaki H, Cui L, Ikeda-Dantsuji Y, Nakae T, Honda J, Yanagihara K, et al. Antibiotic susceptibility survey of blood-borne MRSA isolates in Japan from 2008 through 2011. Journal of Infection and Chemotherapy. 2014;20(9):527-34.

105. Muileboom J, Hamilton M, Parent K, Makahnouk D, Kirlew M, Saginur R, et al. Community-associated methicillin-resistant Staphylococcus aureus in northwest Ontario: a five-year report of incidence and antibiotic resistance. Canadian Joumal of Infectious Diseases and Medical Microbiology. $2013 ; 24$.

106. Levesque S, Bourgault A, Galarneau L, Moisan D, Doualla-Bell F, Tremblay C. Molecular epidemiology and antimicrobial susceptibility profiles of methicillin-resistant Staphylococcus aureus blood culture isolates: results of the Quebec Provincial Surveillance Programme. Epidemiology \& Infection. 2015;143(7):1511-8.

107. Nichol KA, Adam HJ, Roscoe DL, Golding GR, Lagacé-Wiens PR, Hoban DJ, et al. Changing epidemiology of methicillin-resistant Staphylococcus aureus in Canada. Journal of Antimicrobial Chemotherapy. 2013;68(suppl_1):i47-i55.

108. Akanbi OE, Njom HA, Fri J, Otigbu AC, Clarke AM. Antimicrobial susceptibility of Staphylococcus aureus isolated from recreational waters and beach sand in Eastem Cape Province of South Africa. Intemational journal of environmental research and public health. 2017;14(9):1001.

109. Naimi HM, Rasekh H, Noori AZ, Bahaduri MA. Determination of antimicrobial susceptibility patterns in Staphylococcus aureus strains recovered from patients at two main health facilities in Kabul, Afghanistan. BMC infectious diseases. 2017;17(1):737.

110. Nurjadi D, Olalekan AO, Layer F, Shittu AO, Alabi A, Ghebremedhin B, et al. Emergence of trimethoprim resistance gene dfrG in Staphylococcus aureus causing human infection and colonization in sub-Saharan Africa and its import to Europe. Joumal of Antimicrobial Chemotherapy. 2014;69(9):2361-8.

111. Sharma N, Kumar J, Thakur S, Sharma S, Shrivastava V. Antibacterial study of silver doped zinc oxide nanoparticles against Staphylococcus aureus and Bacillus subtilis. Drug Invention Today. 2013;5(1):50-4.

112. Kali A, Stephen S, Umadevi S, Kumar S, Joseph NM, Srirangaraj S. Changing trends in resistance pattern of methicillin resistant Staphylococcus aureus. Journal of clinical and diagnostic research: JCDR. 2013;7(9):1979.

113. Gitau W, Masika M, Musyoki M, Museve B, Mutwiri T. Antimicrobial susceptibility pattem of Staphylococcus aureus isolates from clinical specimens at Kenyatta National Hospital. BMC research notes. 2018;11(1):226.

114. Pantosti A, Sanchini A, Monaco M. Mechanisms of antibiotic resistance in Staphylococcus aureus. 2007.

\section{Supplementary Files}

This is a list of supplementary files associated with this preprint. Click to download.

- ListofFiguresSupplementry.docx 